\title{
AS REGRAS DE QUARTO E VINTENA E DA CONTA DE FLANDRES NO COMÉRCIO PORTUGUÊS DAS ESPECIARIAS (SÉCULO XVI)
}

\author{
Teresa Costa Clain \\ CIDMA - Universidade de Aveiro, Portugal
}

(aceito para publicação em abril de 2018)

\begin{abstract}
Resumo
Os primeiros livros portugueses de aritmética prática apareceram no século XVI, em plena época de expansão marítima. Referimo-nos ao Tratado da Pratica d'Arismetica (1519) de Gaspar Nicolas, à Pratica d'Arismetica de Ruy Mendes (1540) e ao Tratado da Arte de Arismetica de Bento Fernandes (1555). De acordo com o modelo tradicional, os tratados da aritmética portuguesa quinhentista exibem um conjunto de regras que visavam a prática comercial. Entre as regras consideradas clássicas, temos as baratas, as companhias e as ligas. A modelização aritmética presente nas obras portuguesas estende-se a outras regras. Referimo-nos à regra de quarto e vintena e à regra da conta de Flandres, ambas associadas a duas peças fundamentais do comércio português das especiarias - a Casa da Índia e a Feitoria da Flandres.

No contexto da Matemática para o comércio designaremos a regra de quarto e vintena e a regra da conta de Flandres por "regras específicas" do comércio português, dado que não se conhecem outros tratados da mesma época que as contenham. Neste trabalho vamos descrever as duas regras e os problemas associados. Os enunciados propostos pelos autores levam-nos a crer numa aprendizagem por imitação dos problemas resolvidos e numa difusão da Matemática ligada a atividades profissionais.
\end{abstract}

Palavras-chave: Século XVI, aritmética, Portugal, Gaspar Nicolas, Ruy Mendes e Bento Fernandes, Casa da Índia, feitoria da Flandres, regra de quarto e vintena e regra da conta de Flandres.

[THE FOURTH AND TWENTIETH RULE AND THE FLANDRES ACCOUNT RULE FOR THE PORTUGUESE TRADE OF SPICES (SIXTEENTH CENTURY)]

\section{Abstract}

RBHM, Vol. 17, $\mathrm{n}^{\circ} 34$, p. 83-97, 2017 
The first Portuguese books of practical arithmetic appeared in the 16th century, during the period of maritime expansion, namely the Tratado da Pratica d'Arismetica (1519) by Gaspar Nicolas, the Pratica d'Arismetica by Ruy Mendes (1540) and the Tratado da Arte de Arismetica by Bento Fernandes (1555). According to the traditional model, the 16th century Portuguese arithmetic treatises exhibit a set of rules developed for commercial practice. Among the rules considered classic, we have the exchange, the companies and the league's rules. The arithmetic modeling contained in the works also includes some specific rules of the trading Portuguese context. We refer to the fourth and twentieth rule and the Flanders account rule, both of which are associated with two fundamental pieces of the Portuguese spice trade - the House of India and the Factory of Flanders. Such specific rules are quite unusual since no foreign treaties of the same epoch containing them are known. In this work we will describe the two rules and their associated problems. The statements proposed by the authors lead us to believe in a learning by imitation/reproduction of solved problems and in the diffusion of mathematics associated to professional activities.

Keywords: 16th century, arithmetic, Portugal, Gaspar Nicolas, Ruy Mendes and Bento Fernandes, House of India, Factory of Flanders, fourth and twentieth rule, Flanders account rule.

\section{Introdução}

A Rota do Cabo ${ }^{1}$ trouxe à Europa as especiarias a preços atraentes e converteu Lisboa numa cidade com uma atividade comercial intensa onde, como o afirmou Bento Fernandes (Fernandes, 1555, prologo), "florece ho trato da mercancia". A enorme quantidade e variedade de produtos em circulação, bem como o aparecimento de técnicas comerciais cada vez mais complexas exigia que os intervenientes agissem com sabedoria. Os mercadores necessitavam de registar, calcular os ganhos e prever os riscos. Para o efeito era necessário o domínio de conhecimentos, pelo menos básicos, em aritmética. De que aritmética se tratava? De uma aritmética dos algoritmos no sentido do cálculo escrito com a utilização e vulgarização dos números indo-árabes.

$\mathrm{Na}$ teia comercial então criada distinguiram-se instituições entre as quais citamos duas, a feitoria portuguesa da Flandres e a Casa da Índia. A primeira destacou-se no negócio das mercadorias do Oriente na Europa. A segunda na distribuição, armazenamento e comércio das especiarias. Ambas são mencionadas nos tratados portugueses de aritmética, publicados no século XVI e encontram-se ligadas a duas "regras específicas" do comércio nacional, a regra da conta de Flandres e da regra de quarto e vintena.

Os três aritméticos portugueses, Gaspar Nicolas, Ruy Mendes e Bento Fernandes, não ficaram indiferentes ao conteúdo e aplicação dos direitos de quarto e vintena. Podemos depreender das suas próprias palavras o quão importante era que todos ficassem

\footnotetext{
${ }^{1}$ A Rota do Cabo foi a primeira rota marítima regular entre a Europa atlântica e a Índia (Godinho 1963-1971, vol. I, p. 48).
} 
familiarizados com esta regra da Casa da Índia. Deste modo conceberam modelos a utilizar quer pelos contadores do rei, quer pelos mercadores.

A regra da conta de Flandres aparece como um modelo aplicado à "viagem das mercadorias" pela Europa através da feitoria da Flandres. Viajar implicava variações de "preços", "pesos" e "medidas". O próprio capital esteve presente nas praças mais famosas numa procura de aplicações financeiras com vista a um melhor rendimento. Os aritméticos portugueses são atores neste palco de forte interação entre o mundo real e o modelo aritmético, como o descreveu Marques de Almeida (Almeida, 1994,vols. I, II).

\section{A Casa da Índia, a feitoria da Flandres e os mercadores}

\section{A Casa da Índia}

A Casa da Índia foi uma organização portuguesa criada por volta de $1503^{2}$ em Lisboa para administrar os territórios portugueses além-mar, assim como todos os aspetos do comércio externo, navegação, desembarque e venda de mercadorias. Assegurava o monopólio régio da navegação e o comércio do Império português desenvolvido na sequência dos descobrimentos do século XVI. Funcionava como feitoria, alfândega e arquivo central. Entre 1503 e 1755 esteve sedeada no Paço da Ribeira, em Lisboa (atual Praça do Comércio).

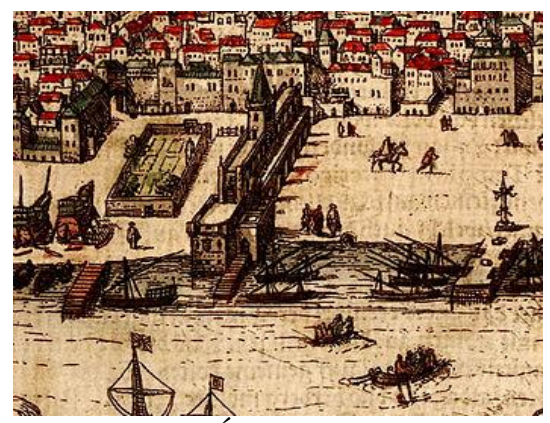

Fig. 1: O Paço da Ribeira onde a Casa da India estava localizada. Perpendicular ao rio Tejo, possuía uma torre central e um terraço frente ao rio (gravura de Braun e Hogenberg in

Civitates Orbis Terrarum, 1572).

As motivações para a criação de uma instituição que organizasse os grandes negócios do Oriente encontram-se descritas nas primeiras páginas do Regimento da Casa da Índia.

“D. Manoel, por graça de Deos Rey de Portugal e dos Algarves daquem e d'alem mar em Africa, Senhor de Guiné e da conquista, navegação, comercio da Ethyopia, Arabia, Pércia e da India: A quantos esta nossa

${ }^{2}$ https://www.infopedia.pt/\$casa-da-india (acedido em 20/08/2017)

RBHM, Vol. 17, no 34, p. 83-97, 2017 
carta de Regimento, virem fazemos saber que considerando nos quam grandes couzas sam os nossos trautos de Guiné e das Indias, a Deos louvores, y quãto proveito deles se segue a nossos Regnos, e naturaes deles, y assi a outras muntas partes da Christandade, e como somos obrigados trabalhar, quanto em nos for, de as taes couzas serem sempre bem regidas e governadas y conservadas, e parescendo nos que por o negocio ser grande e de munta importância y ocupação... " (Peres, 1947, p.3)

O volume avultado de negócios ligados à Rota do Cabo inspirou a redação do documento onde tudo é considerado com pormenor. A expansão territorial foi também sinónimo de expansão comercial e de uma nova realidade económica e social segundo (Almeida, 1993, pp. 18-25).

O que se conhece da Casa da Índia é através do Regimento publicado em 1947 por Damião Peres que se baseou, segundo o próprio afirma, em dois exemplares manuscritos, dos quais um guardado na Biblioteca da Marinha e o outro na Biblioteca Nacional de Portugal. O regimento reparte-se por diferentes secções, desde os regulamentos promulgados em 1509 , às alterações realizadas até 1530 e ainda os diplomas publicados entre 1575 e 1697. O documento descreve a composição do pessoal nas Casas das Índias, da Guiné e da Mina, salientando-se uma estrutura administrativa importante com diferentes categorias de funcionários. O seu autor (Peres, 1947, p. 50) descreve algumas atividades ligadas à instituição, como as compras, as vendas e outras operações comerciais, incluindo a contabilidade, a auditoria e o controlo interno, para além da sua estrutura em termos de pessoal. Tudo é fiscalizado, num sistema em que todos os funcionários trabalham no sentido de não haver lugar a fraudes e incumprimento de tarefas e deveres, sempre com o objetivo de bem servir os mercadores, tal como se pode constatar no capítulo 59 ("Que sejam bem tratados os mercadores").

Poder-se-á pensar que Gaspar Nicolas ou mesmo Ruy Mendes trabalhassem naquela instituição, dado que, falavam dela com muito à vontade nas questões relacionadas com a regra de quarto e vintena. Estaria algum destes aritméticos ligados à formação dos funcionários na Casa da Índia? Não possuindo provas que nos permitam encontrar uma resposta, a probablidade desta suposição ser válida é bastante considerável, basta observar o sentido pedagógico das suas explicações.

\section{A feitoria da Flandres}

A primeira feitoria portuguesa foi fundada em Bruges, na Flandres ${ }^{3}$, em fins do século XIV, após quase dois séculos de presença e atividade de mercadores portugueses no Norte da Europa. Desde o século XIII, registou-se a presença regular de comerciantes portugueses a negociar produtos nacionais (azeite, frutos, peixe, cortiça, mel, sal, vinhos, couros) nas feiras e portos franceses, nas praças comerciais flamengas, em cidades inglesas, no Norte

${ }^{3}$ https://www.infopedia.pt/\$feitorias (acedido em 20/08/2017) 
do Sacro Império Romano Germânico e até na região do mar Báltico, com incentivos régios - esquema de segurança em caso de acidentes ou danos na mercadoria. Alguns desses comerciantes fixavam residência em certas cidades, facto que está na origem dos núcleos de mercadores portugueses que propiciariam a criação de feitorias. No fluxo comercial associado às feitorias nacionais circulavam ainda ouro e pedras preciosas, especiarias, açúcar, madeiras, cavalos, aves exóticas, cereais, sedas, porcelanas, e ainda capitais, como o refere Bento Fernandes (Fernandes, 1555, f. 41 f) sobre "o tomar dinheiro em Inves (Antuérpia)", entre outros produtos em constante movimento no triângulo comercial que envolvia os três continentes europeu, americano e africano.

As feitorias contavam com o trabalho de vários funcionários. O feitor era um funcionário nomeado pelo rei, representando, em território estrangeiro, os interesses da Coroa. Acumulava ainda funções administrativas, diplomáticas, económicas e financeiras. Estava ainda encarregado de gerir o comércio e a comunidade de mercadores. Para além do feitor, poderiam existir outros funcionários como escrivães, almoxarifes, tesoureiros, juízes, cônsules e militares. A feitoria de Bruges funcionava simultaneamente como uma associação de mercadores e uma embaixada, exercendo a justiça na comunidade de mercadores. $\mathrm{O}$ feitor alugava espaços aos mercadores, para além de arbitrar o comércio e implementar um sistema de seguros.

A feitoria de Bruges foi transferida para Antuérpia entre 1488 e 1498 e a este ponto, chegaram não só o açúcar da Madeira, como os produtos orientais e africanos. Estes produtos são referidos com frequência nos livros portugueses de aritmética, encontram-se associados a múltiplos problemas de regra de três, das regras de companhias, das regras de baratas e da regra de quarto e vintena. O papel da feitoria de Antuérpia no circuito comercial da época era de tal modo importante que deu o nome a uma regra, a "Regra da Conta de Flandres".

\section{Os mercadores. $\mathrm{O}$ aritmético e mercador Bento Fernandes}

Como já referimos, com o aparecimento das rotas marítimas Lisboa viu o seu porto tornarse muito ativo comercialmente. Em (Almeida, 1993, pp. 48-65) refere-se que esta cidade atraiu mercadores estrangeiros. Entre estes há que distinguir os que vinham a Portugal negociar e os que se fixavam na cidade. Para além de Lisboa, e já a partir do século XIV, podemos encontrá-los noutros pontos comerciais, como na cidade do Porto e em alguns pontos comerciais no Algarve. Quem eram os mercadores portugueses? Em (Barata, 1998, pp. 215, 216) cita-se António Sérgio que menciona uma burguesia comercial e cosmopolita que já atuava a partir de finais do século XIV. O mesmo autor refere António Borges Coelho que caracteriza uma "alta burguesia marítima agrícola" na base da expansão ultramarina, "como forma de impor aos senhores o seu próprio reconhecimento".

$\mathrm{Na}$ figura de mercador influente na cidade do Porto, temos Bento Fernandes que foi também aritmético. A atividade comercial de Bento Fernandes é hoje bem conhecida e data de 1552, como o refere Barros (Barros, 2013, p. 62), época de mudança na economia 
da cidade do Porto. Esta data marcou o início da exploração do mercado do açúcar do Brasil.

Ainda segundo (Barros, 2013, p. 62), Fernandes dedicava-se à importação e distribuição de têxteis ingleses, flamengos e castelhanos, armazenando estes produtos na sua loja da rua da Ponte de São Domingos. O comércio dos têxteis está bem presente no Tratado da Arte de Arismetica nos problemas que envolvem estes produtos. Os fólios $54 \mathrm{e}$ 55 daquele tratado são dedicados a problemas de negócio de panos, onde o autor (Fernandes, 1555, f. 54 v) enuncia um problema que ilustra bem a sua atividade: "Hum mercador vẽdeo hũa peça de pano por .8. cruzados e ganha nelas a .15. por .100. . Pregũto se a ele vẽderã por .14. cruzados quãto ganhara por .100.”.

Bento Fernandes pertenceu ainda à rede do banqueiro António da Fonseca e associados e viria a casar com Genebra Fonseca, irmã de António Fonseca, por volta de 1530. António Fonseca estava já inserido numa rede familiar de negócios, constituída por mercadores cristãos-novos, que atuava em Lisboa e no Porto e à qual se juntou Fernandes através do casamento. A rede, então existente, projetou os seus negócios nas comunidades portuguesas do Mediterrâneo, especialmente a que se fixou em Roma, veja-se (Barros, 2013, p. 63). No tratado (Fernandes, 1555, f. 53 v) exibem-se também as equivalências monetárias em território italiano tais como o exemplo da troca de moeda entre Florença e Veneza: "Hũ mercador ha d'aver d'outro .320. cruzados de Florẽça e elle quer que lhos de venezianos e os venezianos valẽ mais .4 e e $\frac{1}{2}$ por .100 . pregũto quãtos the deve dar venezianos". Estes problemas poderiam ter sido destinados a mercadores nacionais com negócios nas cidades italianas que recorriam a este aritmético/mercador para verem as suas dúvidas esclarecidas.

Bento Fernandes, associado a António Fonseca, atuava numa rede com patronos influentes entre os quais o Infante D. Luís a quem dedicou o Tratado da Arte de Arismetica. O negócio de Fernandes rapidamente se transformou na movimentação de letras, no cálculo de câmbios e o seu tratado espelha muitas destas operações: "Hum mercador tẽ posto em cãbio .750. cruzados e quer tiralos do cãbio ẽ tres sortes de moedas porque vay caminhado pera logares deferẽtes...”, veja-se (Fernandes, 1555, f. 48 v). Também os pedidos de crédito se encontram entre as situações propostas pelo aritmético.

Todos estes negócios parecem ter confluído no sentido de colocar Fernandes na posição de um mercador abastado que ampliou a sua rede de atuação ao nível da Flandres por intermédio de Tristão Rodrigues Vila Real, um cristão-novo do Minho, com negócios no Porto, como se afirma em (Barros, 2013, p. 67). Este mercador liderava uma rede que abrangia muitos setores, tais como, importação de têxteis europeus, açúcar, livros e pastel dos Açores.

\section{A regra de quarto e vintena da Casa da Índia}

A regra de quarto e vintena ocupa uma posição de destaque nas aritméticas portuguesas. Está presente em todos os tratados e foi certamente uma das bases de motivação para a 
elaboração dos tratados lusitanos, dado que, do ponto de vista fiscal, estava ligada a uma fonte geradora de avultadas receitas para o reino.

âdoatículaprimeírn.

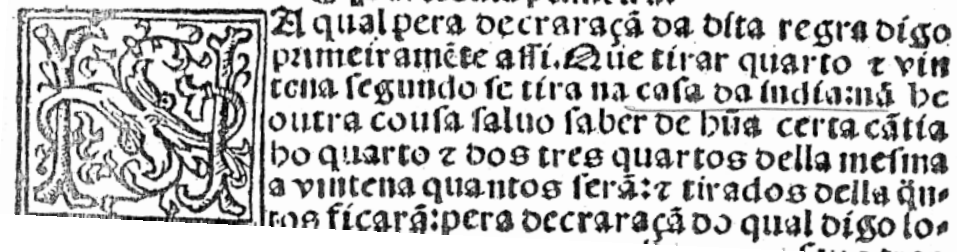

Fig. 2 Introdução à regra de quarto e vintena na Pratica de Ruy Mendes (Mendes, 1540, f. $80 \mathrm{v}$ )

Podemos confirmar a importância da regra nas palavras dos próprios autores quando introduzem o assunto. Diz Ruy Mendes:

"Que tirar quarto e vintena segundo se tira na Casa da Índia nã he outra cousa salvo saber de hũa certa cãtia ho quarto e dos tres quartos della mesma a vintena quantos sera e tirados della quantos ficarã”. (Mendes, 1540$, f. $80 \mathrm{v})$

Também Bento Fernandes fez uma introdução semelhante:

"A regra de quarto e vintena se diz asi por rezã que na Casa da Índia da cidade de Lixboa se paga ho quarto e vintena de toda a especiaria e mercadoria que vẽ da India .s. tira se primeiro ho quarto e depois a vintena para el rei nosso senhor". (Fernandes, 1555, f. 38 v)

O quarto e vintena era um imposto que tinha por base a cobrança de um quarto mais a vintena dos restantes três quartos, ou seja, $\frac{1}{4}+\frac{1}{20} \times \frac{3}{4}=\frac{23}{80}$ da quantidade inicial de mercadoria $(x)$.

Baseando-se nesta realidade fiscal, Gaspar Nicolas, Ruy Mendes e Bento Fernandes abordaram o assunto de modo semelhante e através de um conjunto de problemas que traduzem vários cenários, desde a simples aplicação do modelo para o cálculo do imposto, até às situações em que se confirmam quebras nas mercadorias transportadas durante as longas viagens marítimas, com consequente prejuízo para os mercadores.

Era importante conhecer o valor do imposto a pagar, através da aplicação da regra de três segundo o modelo 4 80---23--- $x$ e também o que restava para benefício do mercador através do modelo 80---57--- $x$ e a mesma regra de três. Os autores quinhentistas aplicaram

${ }^{4}$ Usando a regra de três, se o quarto de 80 e a vintena dos seus três quartos são 23, o quarto de $x$ e a vintena dos seus três quartos, quantos serão?

RBHM, Vol. 17, n 34, p. 83-97, 2017 
estes modelos aritméticos à resolução de uma lista exaustiva de problemas, como este que Ruy Mendes enuncia:

“Hũa nao partio da India com .500. quintaes de pimenta: e chegando a Portugal achouse nella de quebra a razam de .6. por cento: preguntase primeiramente com quantos quintaes chegou a Portugal e esto sabido preguntase mais o quarto deles e a vintena dos seus tres quartos quantos seram: e tirados deles mesmos quãtos ficarã”. (Mendes, 1540, f. 82 f)

O texto refere a perda de uma parte da carga de pimenta na viagem entre a Índia e Portugal. Os produtos transportados poderiam sofrer danos ou uma parte desaparecer por atos de pirataria, daí estarem previstas situações de quebra. Dos textos depreende-se que os direitos de quarto e vintena da Casa da Índia eram cobrados antes de ser deduzida a quebra que as mercadorias sofriam no decurso das viagens e os mercadores manifestavam-se contra esta medida. Segundo (Mendes, 1540, f. 82 f) com a "regra de tirar a quebra e quarto e vintena" refere-se que a mercadoria transportada podia sofrer uma quebra de $6 \%$, $8 \%, 9 \%$ ou até $12 \%$. Em (Almeida, 1994, vol. I, p. 256) afirma-se que se conhecem casos de $30 \%$ e $40 \%$. Se pensarmos que o imposto da Casa da Índia correspondia a uma taxa de $28,75 \%$, uma perda acarretava grandes prejuízos para os mercadores.

O tratado de Gaspar Nicolas (1519) reflete já uma preocupação relativamente às situações de quebra de mercadoria. Este autor apostou numa prática da regra mesmo em problemas onde não indicava o produto comercializado, pondo em destaque simplesmente a prática do algoritmo. O bom conhecimento demonstrado por Nicolas na aplicação dos direitos de quarto e vintena na Casa da Índia pode levar-nos a supor que se dirigia a um público trabalhador nessa instituição mas também ao mercador. O autor refere (Nicolas, 1963 , f. 17) uma quebra na mercadoria entre $6 \%$ e $12 \%$ e propõe enunciados onde não segue os procedimentos previstos, no caso de uma perda efetiva de mercadoria ${ }^{5}$. $\mathrm{O}$ seu objetivo era a prática do algoritmo, o que nos vem reforçar a ideia de um ensino baseado na repetição do modelo estabelecido.

O modo como Nicolas, Mendes e Fernandes apresentam os problemas de quarto e vintena deixa no ar três objetivos como o referiu Clain (Clain, 2015, p. 18). Com efeito, cada enunciado é redigido para calcular três valores distintos: Um quarto da mercadoria $a$, a vintena dos três quartos do restante $b$ e finalmente o que o mercador vai guardar depois de liquidados os impostos $c$. Podemos testemunhar a presença desta tricotomia $a, b, c$ nos enunciados para a prática da regra de quarto e vintena, como foi apresentado por Clain (Clain, 2016, p. 352). Será um simples efeito do algoritmo proposto baseado no cálculo de resultados intermédios, como $a$ e $b$ ou estaremos perante uma subdivisão intencional resultante de uma divisão particular do imposto cobrado? Uma interpretação possível estará

\footnotetext{
${ }^{5}$ Podemos pensar que na data de edição da sua obra, os mercadores deparavam-se com o problema das perdas sem que a Casa da Índia fosse sensível a este prejuízo, não sabemos o que aconteceu entre 1519 e 1540, ano da publicação do tratado de Mendes dado que o autor nada nos diz a este respeito.
} 
ligada a um procedimento pedagógico dos autores no sentido de decompor a resolução de cada problema em três cálculos elementares e portanto, de maior alcance para o aprendiz ${ }^{6}$.

\section{A regra da conta de Flandres}

A regra da conta de Flandres baseava-se numa prática de conversão com recurso à regra de três. Na feitoria da Flandres era necessário converter moedas, "pesos" e "medidas". Sobre a moeda, ficamos a saber que na feitoria circulava a "livra", o "soldo" e o "dinheiro". Na praça de Lisboa a moeda era o "real". A equivalência monetária é apresentada nos quadros que se seguem e vem da informação que se encontra em (Fernandes, 1555, f. 40).

Tabela 1: Moeda na feitoria da Flandres

$\begin{array}{lllll} & \text { Livra } & \text { Soldo } & \text { Dinheiro }^{\mathbf{7}} & \text { Mita }^{\mathbf{8}} \\ & & & & \\ \text { Livra } & 1 & 20 & 240 & 5760 \\ \text { Soldo } & 1 / 20 & 1 & 12 & 288 \\ \text { Dinheiro } & 1 / 240 & 1 / 12 & 1 & 24 \\ \text { Mita } & 1 / 5760 & 1 / 288 & 1 / 24 & 1\end{array}$

Tabela 2. Equivalência entre a moeda na Flandres e em Portugal

\section{Moeda na Moeda portuguesa \\ feitoria Flandres $\quad\left(\right.$ Real $\left.^{9}\right)$}

$\begin{array}{ll}\text { Livra } & 1200 \\ \text { Soldo } & 60 \\ \text { Dinheiro } & 5 \\ \text { Mita } & 1 \text { e } 1 / 4 \text { cetil }^{10}\end{array}$

\footnotetext{
${ }^{6} \mathrm{Na}$ aritmética de Guiral Pacheco publicada no século XVII, os direitos de quarto e vintena estão ligados à "conta de cento" (Pacheco, 1624, ff. 146, 147). Diz-nos este autor: "A meu ver, he milhor fazer a conta de cento assim pera os naturaes, como pera dar contas aos estrangeiros..." (Pacheco, 1624, f. 146v). A regra de três é aplicada a dois modelos: “...se 80. me dão de dereitos vinte, \& tres, cento, quantos me darão, feita a conta, sairão 28 . \& tres quartos por cento...” (Pacheco, 1624, f. 147f) e “...tanto montará ficar de 80..57. que de cento setenta, \& hum, \& hum quarto..." (Pacheco, 1624, f. 147f). Guiral Pacheco propõe uma simplificação do algoritmo associado à regra de quarto e vintena usando a noção de percentagem e o número misto $28 \frac{\mathrm{a}}{4}$ (por cento). O autor deixou por tratar os problemas que "quarto e vintena", ficando-se pela referência aos "autores antigos" e deu lugar a um conjunto de enunciados sobre os direitos cobrados na alfândega de Lisboa. Conhecem-se algumas alterações no decurso do século XVII relativamente ao comércio externo o que acabou por ser espelhado na Flor d'Arismetica Necessaria de Pacheco.

${ }^{7} \mathrm{O}$ "dinheiro" pode também designar-se por "grosso".

${ }^{8}$ A "mita" foi emitida na Flandres a partir de 1418

${ }^{9} \mathrm{O}$ sistema "libra-soldo-dinheiro" existiu em Portugal até 1435, altura em que a libra foi abolida e substituída pelo real branco.
}

RBHM, Vol. 17, n 34, p. 83-97, 2017 
A regra propunha os algoritmos necessários aos mercadores para realizarem com segurança os negócios na Flandres. Bento Fernandes (Fernandes, 1555, ff. 40-42) é o autor que mostra uma maior motivação para exibir um conjunto de problemas mais diversificado. Nos enunciados está presente a sua atividade como mercador, quer no negócio de bens, quer nas operações de câmbio. Ruy Mendes e Gaspar Nicolas enunciam algumas questões sobre o comércio do açúcar, tais como podemos ler o seguinte:

Na qual digo primeiramẽte assim: pode por caso que arrova de frãdes tẽ 25 arrates ou livras como la se chamã e que hũ homẽ qr vẽder laa 16 arrovas d'açucare a 5 dinheiros o arratal. Pregũta se quantas livras se montaria nelas. (Mendes, 1540, f. 83)

Na época a que nos reportamos, os portugueses tinham o monopólio do comércio do açúcar na Europa. Era um produto produzido na ilha da Madeira, daí não ser de admirar encontrar enunciados de problemas sobre este negócio. Gaspar Nicolas acrescenta uma forte motivação para a regra: resolver questões que envolvem as "mitas", moeda estrangeira para os mercadores nacionais. Segundo afirma (Nicolas, 1963, f. 35 v), “...muytos sam arysmeticos e has vezes se embaraçam na conta das mytas". Sem dúvida que os problemas exibidos procuram responder às dúvidas dos mercadores e facilitar-lhes as operações na Flandres através da repetição do algoritmo proposto, ou seja, a regra de três aplicada a práticas de conversão monetária.

No nosso entender a abordagem de Nicolas à regra está muito próxima da que realizou Ruy Mendes. Os dois trataram de problemas de vendas e da prática das unidades. Também observamos uma pobreza na informação sobre os produtos comercializados na Flandres dado que, a maioria dos problemas relata o negócio do açúcar e certamente existiriam outros produtos e outras transações. É Bento Fernandes que nos dá uma dimensão diferente dos negócios na Flandres que, no nosso entender, espelha a realidade da atividade dos mercadores naquela praça. A juntar aos problemas já conhecidos sobre o comércio do açúcar, Bento Fernandes propõe outros, como já referimos, que exibem uma maior diversidade em termos de produtos e de operações de conversão. $\mathrm{O}$ enunciado seguinte demonstra bem a atividade deste mercador no negócio dos tecidos na Flandres.

"Cõprey em Inves .122. ãnas de toalhas a preço de.42. dinheiros a ãna e quero saber o que mõta nelas. E pera o saberes aveis de multiplicar as .122. anas pelos .42. dinheiros como vos mostrei na regra de multiplicar que atras fiqua e achareis que fazẽ assi .5124. dinheiros ou grossos que

${ }^{10} \mathrm{O}$ início da expansão ultramarina portuguesa em 1415 foi assinalado com a criação de uma nova moeda: o cetil de Ceuta. 
tudo he hũa cosa se quereis saber quãtas livras ou soldos serã partireis ao .5124. dinheiros por .240. dinheiros que tem a livra e vem .21. livras de grossos e ainda ficam .84. dinheiros os quais partireis por .12. dinheiros que tẽ o soldo e vẽ.7. soldos e nã fica nada por partir assi que direis que cõprãdo ẽ Inves .122. ãnas de toalhas a .42. dinheiros a ãna se mõtã .21. livras de grosso e .7. soldos e se quereis saber quãto valẽ ẽ Portugal as ditas .21. livras e .7.soldos multiplicareis as .21. livras por .1200. reaes que val cada livra e fazẽ.25200. reaes e multiplicareis os 7 . soldos por 60 reaes que val cada soldo e fazẽ .420. reaes e assi fazẽ em soma .25620. reaes e assi he feita como podeis provar". (Fernandes, 1555 , f. 40)

Na resolução apresentada observamos duas etapas. Na primeira apura-se o valor da venda na Flandres e na segunda determina-se o resultado em moeda portuguesa. Todos os problemas enunciados assentam numa vasta teia de conversões e o autor repara que algumas destas operações são muito trabalhosas: "pera ho saber vos he necessario ter boa memoria porque ainda a cõta he pequena he hũ pouco trabalhosa", tal como o próprio afirma (Fernandes, 1555, f. 40 f).

Bento Fernandes (Fernandes, 1555, f. 41) descreve ainda operações de câmbio sob a designação da regra da conta de Flandres. Os relatos de transações entre a Flandres e Medina del Campo estão presentes na sua obra. Pelos enunciados propostos podemos imaginar as vivências do autor como mercador e cambista, vejamos um exemplo.

"Outra conta de Frãdes sobre ho tomar do dinheiro a pagar em Medina (Medina del Campo - Espanha)

Porque algũs mercadores sobre ho tomar ou dar do dinheiro ha cãbio ẽ Inves pera pagar ẽ Medina del Cãpo ou ẽ outra qualquer feira d'Espanha ou tomado e dado ẽ Espanha pera lhe respõderẽ ẽ Inves nã sã tam espertos nẽ esprimétados nesta cõta como ho sã os framẽgos e italianos que andã mais corrẽtes neste cõtratar. E por ser cousa muy necessaria aos tratãtes e mercadores farei aqui declaraçã pera saber a maneira que se ha de ter no fazer de semelhãtes contas e no dar e tomas do dinheiro que nã sejais enganados e pera milhor ẽtenderdes vos darei aqui hũa rezã. E digo que eu tomei é Inves .124. livras de grossos pera pagar ẽ Medina del Cãpo a rezã de .69. grossos o ducado e pera milhor vos declarar digo que eu tomei é Inves .69. grossos pera dar em Medina por cada .69. grossos hum ducado e quero saber quãtos ducados ey de pagar em Medina pelas ditas .124. livras de grossos e quãto perco por .100. em tomar o dito dinheiro. Pera o que vereis: primeiro quantos grossos haa em .124. livras a razã de .240. grossos que tẽ a livra e achareis que há .29760. grossos e estes party per .69. grossos que vos tomais ho ducado 
há pagar ẽ Medina e achareis que vẽ a ser .431. ducados $e \frac{7}{23}$ aos do ducado. Assi que direis que .431. ducados e $\frac{7}{23}$ aos de ducado aveis de pagar ẽ Medina del Cãpo pelas .124. livras de grossos que recebestes ẽ Inves como podeis provar. E se quereis saber a quãto perdeis por cêto vede quãto valẽ .124. livras de grossos a razã de .3. cruzados a livra e achareis que sã .372. cruzados que valẽ.148800. reaes he por eles aveis de pagar .431 . cruzados e $\frac{7}{23}$ aos de cruzado é Medina agora tiray de .431. cruzados e $\frac{7}{23}$ aos de cruzado .372. cruzados restã assi .59 . cruzados e $\frac{7}{23}$ aos de cruzado e tatos cruzados perdestes $\backslash$ pera saber quãto vẽ por .100. ireis há regra de tres dizẽdo assilse em .372. cruzados que recebi ẽ Inves perdi .59. cruzados e $\frac{7}{23}$ aos de cruzado quãto perco por .100. fazey a regra e achareis que perdeis a .15. por .100.e $\frac{65}{69}$ aos de cruzado como podeis provar e deste modo fareis as semelhãtes". (Fernandes, 1555, f. 41f)

Bento Fernandes começa por referir que vai apresentar uma situação de câmbio, onde os mercadores mais experimentados são os flamengos e os italianos, sendo de extrema importância que os outros mercadores intervenientes façam esta operação sem enganos. O problema consiste em usar moeda de Antuérpia para pagar em Medina del Campo. É uma operação de câmbio que assenta sobre dois pilares, numa primeira fase a conversão monetária, seguindo-se o cálculo de uma percentagem (Perder/ganhar no câmbio, neste caso o autor refere uma perda). O enunciado descrito é claro, no entanto, a resolução proposta leva-nos a sucessivos esquemas de conversões, nem sempre claros e sem serem explicitados os objetivos intermediários. Pelo exposto, aqueles que tentassem aprender sem mestre, deveriam ter algumas dificuldades.

Tendo em conta a natureza dos problemas exibidos e ligados ao comércio português, podemos aqui antever que os três autores teriam vivências profissionais diferentes. No discurso de Bento Fernandes há uma referência notória a Flandres e a Medina del Campo, duas grandes praças financeiras muito frequentadas por mercadores nacionais e provavelmente pelo próprio Bento Fernandes ou por outros mercadores que lhes fossem próximos. Em (Ribeiro, 2012, p. 25) estudou-se a importância da firma de Simon Ruiz, banqueiro e mercador de Medina del Campo no século XVI. A circulação de mercadores, mercadorias e crédito nas feiras de Medina é também referida em (Barrio, 2007, pp. 30, 32). Simon Ruiz deixou bem documentada a sua atividade como mercador e cambista. Nesta documentação Vega menciona os mercadores nacionais que frequentavam as feiras e provinham de diferentes partes de Portugal, como Coimbra, Lisboa, Porto, entre muitas outras cidades portuguesas (Vega, 2004, pp. 237, 249). Não se conhecendo uma ligação direta a Bento Fernandes, as hipóteses dela ter existido são bastante fortes, dado que, os problemas de câmbio que Fernandes resolve não são uma mera ficção. O autor 
descreve uma realidade ligada à vida do mercador que frequentava as feiras de Medina, face a algumas dificuldades ligadas às operações de conversão. Como mercador internacional e inserido numa rede que atuava em diferentes áreas do mundo mercantil, Fernandes pode ter atuado não só por interesse próprio mas também como formador, o que era um hábito na época a que nos reportamos.

\section{Conclusão}

As aritméticas práticas portuguesas, à semelhança das obras escritas noutros países para o mesmo fim, apresentaram modelos aritméticos e acompanharam uma tendência para responder às necessidades através da formação dos mercadores como o referem os seus autores. A perceção da necessidade de modelos eficazes no quotidiano dos negócios levou os três aritméticos a escrever sobre dois temas "locais" e relativos aos negócios nacionais com projeção internacional, como o foi o comércio das especiarias. A regra de quarto e vintena propõe um modelo para o cálculo de um imposto na Casa da Índia sobre as mercadorias do Oriente. A regra da conta de Flandres aparece como um modelo de conversão associado às variações de "preços", "pesos" e "medidas". Os aritméticos portugueses não ficaram indiferentes às interações entre o mundo real e os modelos aritméticos. Nos tratados aparece um conjunto de problemas sobre temas ligados ao contexto comercial nacional. Tendo presente os conteúdos das três obras referidas podemos colocar a seguinte questão: Para quem escreveram os aritméticos quinhentistas? Pondo se parte a dedicatória ao mecenas a quem, por exemplo, Gaspar Nicolas pretende esclarecer dúvidas, o público visado não aparece de forma explícita. Bento Fernandes refere mercadores e tratantes, Gaspar Nicolas dá respostas às dúvidas que lhe tinham sido colocadas quando se deslocava à Casa da Índia, onde há mercadores e ainda todos os funcionários daquela instituição. Ruy Mendes menciona os mercadores e outros, sem especificar quem. Podemos por a hipótese de estar perante três autores e também formadores em práticas comerciais, sem enganos, realizadas com honestidade e através de modelos aritméticos credíveis. Pelo modo de atuar, esclarecer e ensinar, os autores preparavam os mercadores e as lides necessárias aos grandes negócios. Nos discursos exibidos nas obras entende-se que os mercadores deviam ser esclarecidos e informados e estar a par com outros mercadores considerados mais sábios nas transações, como o diz Bento Fernandes sobre a mestria de flamengos e italianos. Para o mercador era necessário aplicar a regra e para os menos instruídos, a regra deveria ser clara e simples. Os casos mais complexos cabia aos aritméticos resolvê-los.

Os nossos aritméticos são atores neste palco de forte interação entre o mundo real e o modelo aritmético e, como afirma Bento Fernandes "Mathemática he ho assento, fundamento e escada segura pera sobir aas outra sciencias (...) porque pera alcançar as outras sciencias he necessário conta, peso e medida" (Fernandes, 1555, prologo). As suas palavras traduzem uma forte compreensão do papel dos modelos aritméticos para uma representação da realidade comercial e ainda, uma aproximação ao pensamento matemático, presente neste tipo de tratados. 


\section{Bibliografia}

ALMEIDA, António Augusto Marques. 1993. Capitais e capitalistas no comércio da especiaria. O eixo Lisboa-Antuérpia (1501-1549). Aproximação a um Estudo de Geofinança. Edições Cosmos. Lisboa.

ALMEIDA, António Augusto Marques. 1994. Aritmética como descrição do real (15191679). Imprensa Nacional, Casa da Moeda, 2 vols. Lisboa.

BARRIO, Antonio Sánchez. 2007. Ferias y finanzas, siglos XVI y XVII. Direção de A. Barrio, coordenação de F. González. Fundación Museo de las Ferias. Valladolid.

BARATA, Filipe Themudo. 1998. Navegação, comércio e relações políticas: os portugueses no Mediterrâneo Ocidental (1385-1466). Fundação Calouste Gulbenkian. Lisboa.

BARROS, Amândio. 2013. Os negócios e a aritmética. Bento Fernandes e as redes cristãsnovas do Porto no século XVI. Em A. Andrade et al. (eds.) Humanismo, Diáspora e Ciência (Séculos XVI e XVII). 51-74. Biblioteca Pública Municipal do Porto, Porto.

CLAIN, Teresa Costa. 2015. La Pratica d'Arismetica de Ruy Mendes dans le contexte des arithmétiques ibériques. Revue d'histoire des mathématiques, 21(1). 5-39. Paris.

CLAIN, Teresa Costa. 2016. Les règles d'un quarte et un vingtième et des comptes de Flandre comme modélisation du réel. Em L. Radford, F. Firinghetti e T. Hausberg (eds.) Proceedings of the 2016 ICME Satellite Meeting, HPM 2016. 351-358, em Montpellier, julho 18-22, 2016.

FERNANDES, Bento. 1555. Tratado da Arte de Arismetica. Francisco Correa. Porto.

GODINHO, Vitorino Magalhães. 1963-1971. Os descobrimentos e a economia mundial. Editorial Presença, Vol. I. Lisboa.

MENDES, Ruy. 1540. Pratica darismetica nouamente agora composta pelo licenciado Ruy Mendez: na qual se descraram por boa ordem e craro estilo as quatorze especias darte darismetica .\&. as sete dellas por numeros inteyros e as outras sete por numeros quebrados: e assi mesmo trinta e cinco regras da dita arte muito sortil e breue e craramente decraradas. Germão Galharde. Lisboa.

NICOLAS, Gaspar. 1963. Tratado da Pratica d'Arismetica. Edição fac-similada da edição de 1519, Livraria Civilização, Porto.

PACHECO, Afonso Villafanhe Guiral. 1624. Flor da Arismetica Necessaria. Geraldo da Vinha. Lisboa.

PERES, Damião. 1947. Regimento das Cazas das Índias e Mina. Universidade de Coimbra. Coimbra.

RIBEIRO, Ana Sofia. 2012. A endogamia em redes mercantis da "Primeira Idade Global". O caso da rede de Simon Ruiz (1553-1597). História, Revista da FLUP, 2(IV), 23-40. Porto.

VEGA, Anastasio Rojo. 2004. Guía de Mercaderes y Mercaderías en las Ferias de Medina del Campo. Siglo XVI. Fundación Museo de las Ferias. Valladolid.

This work was supported in part by the Portuguese Foundation for Science and Technology (FCT-Fundação para a Ciência e a Tecnologia), through CIDMA - Center for Research and Development in Mathematics and Applications, within project UID/MAT/04106/2013. 
As regras de quarto e vintena e da conta de Flandres no comércio português...

Teresa de Jesus Costa Pereira Caracol Clain

E-mail: costa.jesus.teresa@ua.pt

CIDMA- Centro de Investigação e

Desenvolvimento em Matemática e Aplicações,

Departamento de Matemática - UA - Aveiro -

Portugal 